\title{
Atividades experimentais de Física da revista Ciência Hoje das Crianças ${ }^{+*}$
}

Jéssica Taynara Martins ${ }^{1}$

Mestranda do Programa de Pós-Graduação em Ensino de Ciências

e Humanidades - Universidade Federal do Amazonas, Amazonas

Elrismar Auxiliadora Gomes Oliveira ${ }^{l}$

Programa de Pós-Graduação em Ensino de Ciências e Humanidades

Universidade Federal do Amazonas

Manaus - AM

\section{Resumo}

A revista Ciência Hoje das Crianças (CHC), criada pela Sociedade Brasileira para o Progresso da Ciência, se destaca como material paradidático de divulgação científica na educação básica brasileira por sua distribuição pelo Programa Nacional do Livro e do Material Didático (PNLD) no Brasil. Desde o final do século XX são realizados estudos sobre a importância das atividades experimentais no ensino de Ciências que objetive a alfabetização científica. As pesquisas recomendam que o encaminhamento das atividades deve partir de um problema, não se limitando à manipulação ou observação. Ressaltam também que as crianças dos anos iniciais de escolaridade são capazes de fazer reflexões e buscar explicações, indo além da mera execução de roteiros ou da contemplação. Assim, o objetivo desse trabalho é apresentar a análise das atividades experimentais de Física propostas na CHC. O resultado mostra que a CHC está na contramão do que recomendam as pesquisas em ensino de Ciências. As atividades experimentais apresentam características empírico-indutivistas marcadas por uma visão rígida da Ciência. Permitem pouca ou nenhuma liberdade para atuação criativa e reflexiva dos estudantes, sem espaço para erro ou discussão dos resultados. A revista não é um material didático e não explicita entre seus objetivos a alfabetização

\footnotetext{
${ }^{+}$Experimental Physics activities of Ciência Hoje das Crianças journal

* Recebido: outubro de 2019. Aceito: julho de 2020.

${ }^{1}$ E-mails: martinsjessica56709@gmail.com; elrismar@gmail.com
} 
científica. Porém, considerando as pesquisas em ensino de Ciências das últimas décadas, acreditamos que um material que pode compor as bibliotecas de mais de 150 mil escolas públicas brasileiras não pode encaminhar concepções estereotipadas da Ciência como, por exemplo, a visão empírico-indutivista. Pelas dimensões do PNLD e sua política de avalição de materiais distribuídos, a CHC deveria se destacar como mediadora entre as pesquisas e o ensino nas escolas.

Palavras-chave: Ensino de Ciências; Divulgação Científica; Natureza da Ciência.

\section{Abstract}

The Ciência Hoje das Crianças (CHC) journal, created by the Brazilian Society for the Advancement of Science, stands out as a material for scientific dissemination in Brazilian basic education due to its distribution through the Programa Nacional do Livro e do Material Didático (PNLD) in Brazil. Since the end of the 20th century, studies have been carried out on the importance of experimental activities in science education aiming at scientific literacy. Research recommends that the routing of activities should start with a problem, not limited to manipulation or observation. They also emphasize that children in the early years of school are able to reflect and seek explanations, going beyond the mere execution of scripts or contemplation. Thus, the objective of this work is to present the analysis of the experimental activities of Physics proposed in the CHC. The result shows that the $\mathrm{CHC}$ is in the opposite direction of what science teaching research recommends. The experimental activities have empirical inductive characteristics marked by a rigid view of science. They allow little or no freedom for students' creative and reflective performance, with no room for error or discussion of results. The journal is not a teaching material and does not make scientific literacy among its objectives. However, considering the science teaching research of the last decades, we believe that material that can compose the libraries of more than 60 thousand Brazilian public schools cannot lead to stereotyped conceptions of Science, such as, for example, the empirical inductive view. Due to the dimensions of the PNLD and its evaluation policy of the distributed materials, the CHC should stand out as a mediator between research and teaching in schools. 
Keywords: Science Teaching; Scientific Divulgation; Nature of Science.

\section{Introdução}

De acordo com informações do sítio do Instituto Ciência Hoje ${ }^{2}$ (ICH) a revista Ciência Hoje das Crianças (CHC) foi criada pela Sociedade Brasileira para o Progresso da Ciência (SBPC) e tem a faixa etária de 7 a 14 anos como seu público-alvo. Ela é o primeiro periódico brasileiro de divulgação científica para as crianças. Em suas primeiras edições, entre 1986 até 1989, a revista era um encarte de outro periódico, a revista Ciência Hoje, e só no ano 1990 passou a ser publicada separadamente.

A CHC destaca-se como material paradidático e de divulgação científica na educação básica brasileira. É um periódico indexado pela Coordenação de Aperfeiçoamento de Pessoal de Nível Superior (CAPES) e em 1991 passou a ser distribuída pelo Programa Nacional do Livro e do Material Didático (PNLD) ${ }^{3}$. Portaria de $\mathrm{n}^{\circ} 4$, de $1^{\circ}$ de abril de 2016, do Ministério da Educação ${ }^{4}$, divulga a relação dos periódicos selecionados no âmbito do Programa Nacional Biblioteca da Escola - PNBE 2016-2018. Essa Portaria mostra que a CHC estava entre os periódicos distribuídos pelo MEC até 2018.

De acordo com o sítio do ICH, "mais de 60 mil escolas públicas do Brasil recebem a revista em sua biblioteca" . Em 2011, a editora executiva da CHC, em entrevista, cita que mais de 150 mil escolas públicas do Brasil recebiam a revista (ALMEIDA, 2011). Sua importância também é creditada por ser objeto de estudo em várias pesquisas (RIBEIRO; KAWAMURA, 2011; SILVA; PIMENTEL; TERRAZZAN, 2011; ALMEIDA, 2018; GALIETA, 2013; ALMEIDA; GIORDAN, 2014; ALMEIDA; LIMA, 2016).

Conteúdos de Física, Matemática, Biologia, História, Geociências, Astronomia, Química, entre outros, são tratados pela CHC. Nessa abordagem são utilizadas variadas metodologias para apresentar as propostas discutidas em cada edição como, por exemplo, jogos, desafios, textos, curiosidades, histórias em quadrinhos, atividades experimentais.

Desde o final do século XX são realizados estudos sobre a importância das atividades experimentais no ensino de Ciências que objetivem a alfabetização científica. Assim, o objetivo desse trabalho é apresentar a análise das atividades experimentais de Física das edições de 2009 a 2018 da CHC. A análise utilizou exemplares físicos doados pela Secretaria Municipal de Educação da cidade de Humaitá, Amazonas, Brasil (2009 a 2014) e exemplares

\footnotetext{
${ }^{2}$ Disponível em: <http://cienciahoje.org.br/instituto/historia/>. Acesso em: 5 mar. 2019.

${ }^{3}$ Programa de grandes dimensões que distribui gratuitamente materiais didáticos e paradidáticos aos estudantes de escolas públicas brasileiras.

${ }^{4}$ Disponível em:

$<$ http://pesquisa.in.gov.br/imprensa/jsp/visualiza/index.jsp?jornal=1\&data=18/04/2016\&pagina=47>. Acesso em: 18 set. 2019.

${ }^{5}$ Disponível em: <http://chc.org.br/sobre-a-chc/\#: :text=A\%20qualidade\%20de\%20tudo\%20o,mais\%20 diferentes\%20regi\%C3\%B5es\%20do\%20pa\%C3\%ADs>. Acesso em: 20 jun. 2019.
} 
digitais do sítio do ICH (2015 a 2018). Esse trabalho é recorte de uma pesquisa de mestrado, ainda em andamento, acerca da Natureza da Ciência nas propostas de atividades experimentais de Física da revista.

\section{Atividades experimentais - pressupostos teóricos}

As atividades experimentais estão entre as metodologias mais importantes no ensino das disciplinas de Ciências da natureza, sendo defendidas por diversos pesquisadores (ARAÚJO; ABIB, 2003; LABURÚ, 2005; ZOMPERO; LABURU, 2011; BORGES, 2002; CARVALHO 2010; PEREIRA; MOREIRA, 2017).

Laburú (2005) explica que a importância dessa metodologia é de ordem motivacional, instrucional e epistemológica. O motivacional e o instrucional levam os professores a crer que as atividades experimentais aguçam a curiosidade e contribuem para a melhoria da aprendizagem. Na ordem epistemológica estão atributos de convencimento das afirmações teóricas a partir da observação.

Muitas expressões são utilizadas para identificar atividades experimentais. Carvalho (2010, p. 53) cita que nomes como ““aulas práticas' ou 'aulas de laboratório' ou 'laboratório escolar' têm sido utilizados para designar as atividades nas quais os estudantes interagem com materiais para observar e entender os fenômenos naturais".

De acordo com Carvalho (2010), a utilização das atividades experimentais não é recente no ensino de Física e apesar de estar há quase 200 anos sendo praticada em sala de aula como metodologia de ensino, elas ainda são um grande desafio para o professor, principalmente em relação à abordagem de aspectos investigativos.

As atividades experimentais podem ser demonstrativas ou manipulativas, de acordo com a utilização dos materiais. Nas manipulativas, os materiais são disponibilizados aos estudantes para realizarem a atividade. Nas demonstrativas, geralmente somente o professor acessa os materiais e realiza a atividade, enquanto os estudantes observam.

Para além da forma de abordagem, demonstrativas ou manipulativas, as atividades experimentais podem ser encaminhadas a partir do ensino tradicional (fechado) ou investigativo (aberto) (CARVALHO, 2010).

A diferença desses encaminhamentos experimentais é o papel que o professor e o estudante assumem no processo de ensino-aprendizagem. Nos experimentos demonstrativos ou manipulativos, em um ensino tradicional, o professor determina todas as etapas da atividade, cabendo a ele o papel principal no processo. O estudante, por sua vez, é um executor ou observador das atividades propostas, priorizando habilidades operacionais com pouco espaço para o erro, análises e reflexões. Nos experimentos demonstrativos ou manipulativos, em um ensino investigativo, o papel principal no processo ensinoaprendizagem é dos estudantes. O professor pode propor o problema a ser investigado, mas são os estudantes que levantam hipóteses e escolhem os procedimentos buscando soluções para a problemática sugerida pelo professor (CARVALHO, 2010). 
A abordagem demonstrativa investigativa pode ser utilizada quando se necessita realizar o experimento em apenas uma aula, ou quando não há materiais suficientes para todos os estudantes, ou até mesmo quando a experimentação oferece riscos à integridade física (SASSERON; MACHADO, 2017).

Para Azevedo (2004, p. 20) “[...] uma atividade investigativa (não necessariamente de laboratório) é, sem dúvida, uma importante estratégia no ensino de Física e de Ciências em geral". Embora as diversas formas de abordagens das atividades experimentais sejam importantes, é consenso entre os pesquisadores da área do ensino de Ciências que, nessas propostas, se deve priorizar aspectos investigativos. Nesse sentido, Azevedo (2004, p. 21) destaca:

Para que uma atividade possa ser considerada uma atividade de investigação, a ação do aluno não deve se limitar apenas ao trabalho de manipulação ou observação, ela deve também conter características de um trabalho científico: o aluno deve refletir, discutir, explicar, relatar, o que dará ao seu trabalho as características de uma investigação cientifica.

É consenso também que esse encaminhamento, na perspectiva investigativa, contribui potencialmente para compreender, como um dos aspectos da Natureza da Ciência, que a Ciência é um processo humano onde o erro também é parte da construção do conhecimento (CARVALHO, 2010; PEREIRA; MOREIRA, 2017; SASSERON; MACHADO, 2017).

Pesquisadores dessa área também investigam concepções estereotipadas do trabalho científico que podem ser reproduzidas e reforçadas no ensino de Ciências. Gil-Perez et al. (2001) e Cachapuz et al. (2005) ressaltam a importância de se estabelecer uma visão aceitável do trabalho científico, que busque evitar as possíveis deformações que podem ser reproduzidas implícita ou explicitamente na atuação de professores e divulgadores da Ciência. Os autores descrevem sete concepções que devem ser evitadas: 1. Empírico-indutivista e ateórica; 2. Rígida, algorítmica, exata e infalível; 3. Aproblemática e ahistórica; 4. Analítica; 5. Acumulativa de crescimento linear; 6. Individualista/elitista e 7. Socialmente neutra.

Dentre essas, a principal visão deformada apontada por pesquisadores da Ciência é a concepção empírico-indutivista e ateórica que está intimamente relacionada com as atividades experimentais realizadas na perspectiva tradicional. As atividades encaminhadas pelo ensino tradicional caracterizam-se pela neutralidade da observação e da experimentação, além de estarem centradas na crença ingênua de um único método científico, ou seja, atribuem à experimentação o desenvolvimento da Ciência (GIL-PEREZ et al., 2001). Sobre essa concepção, Moreira, Massoni e Ostermann (2007, p. 2), citam que:

Tradicionalmente o curso de fisica e também os livros didáticos privilegiam uma formação acadêmica com enfoque altamente empirista-indutivista, isto é, um enfoque no qual o conhecimento advém da generalização indutiva a partir da 
observação, sem qualquer influência teórica ou subjetiva, e dessa forma capaz de assegurar a verdade absoluta às afirmações cientificas. Nosso pressuposto básico, $e$ frequentemente defendido na literatura, é que essas visões superadas (empiristasindutivistas) da natureza da ciência sustentadas por futuros professores de fisica acabam resultando em práticas docentes inadequadas.

Chalmers (1993) em sua obra “O que é ciência afinal?” dedica dois capítulos à crítica ao pensamento indutivista. Cita que a Ciência passa a ter visões errôneas no processo de indução e que o indutivista tem uma imagem ingênua da Ciência. Para esse autor, o indutivista acredita em um único método científico, concepção relacionada ao senso comum, por acreditar na construção do conhecimento a partir das experiências sensoriais. Chalmers (1993, p. 43) cita que David Hume "sustentava que crenças em leis e teorias nada mais são que hábitos psicológicos que adquirimos como resultado de repetições das observações relevantes". Para Chalmers (1993, p. 44), "o princípio de indução, ou algo semelhante, como ‘óbvio' não é aceitável. O que vemos como óbvio depende demais de nossa educação, nossos preconceitos e nossa cultura para ser um guia confiável para o que é razoável ".

Vale ressaltar que embora a concepção empírico-indutivista seja uma das mais apontadas por pesquisadores da Ciência, Gil-Perez et al. (2001) e Cachapuz et al. (2005), destacam que as concepções estereotipadas da Ciência não são excludentes. A concepção empírico-indutivista integra também o caráter rígido e fechado da Ciência.

Também nessa perspectiva Bachelard (1996) destaca entre os obstáculos epistemológicos a experiência primeira, relacionada ao conhecimento já adquirido pelo estudante, ou seja, como ele entende os fenômenos com base em suas ideias e explicações baseadas no senso comum e em registros empíricos. Bachelard (1996, p. 25) enfatiza que "há ruptura, e não continuidade, entre a observação e a experimentação". Alerta também que após a experiência primeira, as generalizações apressadas sem reflexão marcam o segundo obstáculo: o conhecimento geral. Para o autor, "a busca apressada da generalização leva muitas vezes a generalidades mal colocadas, sem ligação com as funções matemáticas essenciais do fenômeno" (BACHELARD, 1996, p. 70). As generalizações de teorias científicas muitas vezes são eficazes ao substituir teorias que as precederam, contudo, é "possível constatar que essas leis gerais bloqueiam atualmente as idéias. Respondem de modo global, ou melhor, respondem sem que haja pergunta" (BACHELARD, 1996, p. 71). O autor valoriza as contribuições da atividade empírica, mas condena o indutivismo ingênuo.

A facilidade das generalizações apressadas feitas a partir da utilização de metáforas, imagens e analogias que representam os conceitos, são características do indutivismo ingênuo.

A utilização de metáforas, imagens e analogias no ensino de Ciências não é condenada por Bachelard. O autor ressalta que, quando utilizadas devem ser capazes de contribuir para alcançar a racionalização e abstração dos conceitos estudados. Esses 
elementos geralmente são utilizados no ensino de Ciências para facilitar a compreensão dos conceitos científicos, porém, a sua acumulação afeta a abstração dos problemas reais.

Lopes (1996, p. 263) argumenta que o uso excessivo de analogias, metáforas e imagens procura "tornar familiar todo conhecimento abstrato", porém esse uso pode constituir-se em obstáculos epistemológicos.

Entendemos que as atividades experimentais podem contribuir para o objetivo de promover a alfabetização científica se construírem visões mais adequadas do fazer científico, propiciando autonomia e reflexões críticas aos estudantes. Para Sasseron e Machado (2017, p. 32), a alfabetização científica:

concebe o ensino em uma perspectiva problematizadora, participativa, em que os alunos utilizam habilidades típicas das ciências para intervir no mundo. $O$ alfabetizado cientificamente compreende de que modo os conhecimentos científicos estão ligados a sua vida e ao planeta, participando de discussões sobre os problemas que afetam a sociedade.

Os conhecimentos em Ciências, construídos a partir dessas reflexões críticas, possibilitam aos estudantes transformarem o ambiente em que vivem. Para tanto, os estudantes devem ser protagonistas do processo de ensino-aprendizagem. Nesse sentido, Carvalho (2010) afirma que as atividades experimentais podem favorecer a alfabetização científica se os professores reverem seu papel de transmissor, transformando-se em participante do processo de construção dos novos conhecimentos. Nesse encaminhamento Carvalho (2010) e Sasseron e Machado (2017) ressaltam que, seja em atividades experimentais demonstrativas ou manipulativas, deve ser permitido aos estudantes o maior grau de liberdade reflexiva e explicativa. Esses autores, a partir de Nilton Pella (1969) ${ }^{6}$, citam cinco graus de liberdade das atividades experimentais e ainda acrescentam o grau zero. $\mathrm{O}$ Quadro I a seguir apresenta esses graus de liberdade.

Quadro I - Graus de liberdade das atividades experimentais.

\begin{tabular}{|l|l|l|l|l|l|l|}
\hline $\begin{array}{l}\text { Graus } \\
\text { Etapas }\end{array}$ & Zero & I & II & III & IV & V \\
\hline Problema & P & P & P & P & P & E \\
\hline Hipóteses & P & P & P & P & E & E \\
\hline Plano de trabalho & P & P & P & E & E & E \\
\hline Obtenção de dados & P & E & E & E & E & E \\
\hline Conclusão & P & P & E & E & E & E \\
\hline
\end{tabular}

(P) professor; (A) estudante

Fonte: Dos autores, adaptada de Carvalho (2010).

\footnotetext{
${ }^{6}$ PELLA, M. O. The Laboratory and Science Teaching. In: ANDERSEN, H. O. Reading in Science Education for the Secondary School. Londres: The Macmillan Company, 1969.
} 
O Quadro I apresenta os graus de liberdade de zero a cinco. No grau de liberdade zero todas as etapas das atividades são desenvolvidas pelo professor (P), enquanto no grau I a IV professor e estudante dividem os papéis. No grau de liberdade $\mathrm{V}$ é dada a maior autonomia ao estudante, cabendo a ele o desenvolvimento de todas as etapas da atividade. Segundo Sasseron e Machado (2017), as atividades experimentais que podem promover alfabetização científica devem oferecer grau de liberdade IV e $\mathrm{V}$ ao estudante, permitindo que ele realize a maior parte das ações.

Em relação aos limites e possibilidades de aprendizagem de temas de Ciências a partir de atividades práticas investigativas, na faixa etária do público alvo da revista (7 a 14 anos), Carvalho et al. (2010, p. 19) cita que

\begin{abstract}
alunos do anos iniciais do ensino fundamental são capazes de ir além da observação e da descrição dos fenômenos [...] as aulas de Ciências podem e devem ser planejadas para que os estudantes ultrapassem a ação contemplativa e encaminhem-se para a reflexão e a busca de explicações, pois é dessa forma que os estudantes terão a chance de relacionar objetos e acontecimentos e expressar suas ideias.
\end{abstract}

A resolução de um problema, pela experimentação, deve envolver reflexões, relatos, discussões, ponderações e explicações.

Gomes, Borges e Justi (2008, p. 196), com base em uma revisão de pesquisas que abordam os conhecimentos, as habilidades e os processos cognitivos mobilizados durante a realização de atividades práticas, em contextos nos quais os participantes não possuem conhecimentos específicos, relatam que em atividades,

\footnotetext{
de menor complexidade, crianças com sete ou oito anos já compreendem o que significa testar uma hipótese através da experimentação. Elas conseguem também distinguir experimentos conclusivos de experimentos confusos ou indeterminados, possuindo, assim, a base para a aquisição de conhecimentos conceituais $e$ procedimentais mais complexos.
}

Acreditamos que no ensino de Física as atividades experimentais, na perspectiva investigativa em que os estudantes atuem com o maior grau de liberdade, podem contribuir para a compreensão de aspectos teóricos dessa Ciência e de sua natureza.

\title{
III. Metodologia
}

Analisamos todas as edições da CHC do período de 2009 a 2018. São publicadas 11 edições por ano, porém, em 2013 só foram publicadas 10. Assim, foram 109 exemplares analisados.

A pesquisa tem natureza qualitativa e documental (GODOY, 1995) e para análise das atividades experimentais de Física da $\mathrm{CHC}$ utilizamos a técnica da Análise de Conteúdo 
(MORAES, 1999). Essa técnica consta de cinco etapas: preparação; unitarização; categorização; descrição e interpretação.

A preparação foi o primeiro contato com os exemplares da $\mathrm{CHC}$, o momento que iniciamos a identificação das propostas que abordam conteúdos de Física.

A unitarização foi o momento da desmontagem do texto, onde identificamos e destacamos as unidades de análise. Nossas unidades de análise são recortes dos textos da revista que tratam da temática desta pesquisa: atividades experimentais de Física. As atividades experimentais da $\mathrm{CHC}$ abordam temáticas de diversas áreas: Física, Química, Geografia, Astronomia, Biologia, Matemática e Artes. Para identificar as diferentes áreas, analisamos dois aspectos: i) auto-intitulação e ii) conceitos ou expressões específicas das áreas de conhecimento.

Consideramos a auto-intitulação quando a atividade explicita a área de conhecimento a que se refere. Quando a atividade não especifica a área, recorremos à identificação de conceitos ou expressões específicas utilizadas no texto da atividade. Essa primeira classificação nos permitiu identificar as atividades que tratam da Física.

No processo de categorização das atividades que tratam da Física organizamos os dados coletados e classificamos por seus aspectos de semelhanças. A priori nossas categorias seguiram duas perspectivas. A primeira se orientou pelas áreas tradicionais da Física (mecânica, óptica, termologia, eletricidade, magnetismo, acústica, física moderna). Na segunda apresentamos a forma de encaminhamento das atividades experimentais de Física da revista, e a partir da epistemologia, procuramos compreender suas propostas abordagem.

Apresentamos a descrição dos dados obtidos por meio de textos, quadros e exemplos retirados da revista. Na fase da interpretação, fizemos uma exegese dos dados obtidos na descrição a partir do diálogo com a fundamentação teórica. Procuramos caracterizar as atividades experimentais propostas na $\mathrm{CHC}$, fazendo uma análise geral buscando compreender se elas permitem liberdade reflexiva e explicativa, podendo promover a alfabetização científica, como recomendam as pesquisas em ensino de Ciências.

\section{Resultados}

Consideramos como atividades experimentais "atividades nas quais os estudantes interagem com materiais para observar e entender os fenômenos naturais" (CARVALHO, 2010, p. 53).

A maioria das atividades experimentais da CHC foi localizada nas seções denominadas "Experimento", "Atividade" e "Mão na Massa", porém outras seções também as propõem ("Surpresa de aniversário", "Galeria bichos ameaçados" e "Passe o tempo"). Essas atividades tratam de várias áreas: Artes, Matemática, Física, Química, Biologia, Astronomia, Educação Física, Português e Geografia.

A Tabela I a seguir mostra de forma geral as atividades experimentais propostas pela CHC nas diversas áreas do conhecimento. 
Tabela I - Atividades experimentais por componente curricular/área na CHC - edições de 2009 a 2018.

\begin{tabular}{|c|c|c|c|c|c|}
\hline \multirow{2}{*}{$\begin{array}{l}\text { Componente } \\
\text { curricular(área) }\end{array}$} & \multicolumn{4}{|c|}{ Seções } & \multirow[b]{2}{*}{ Total } \\
\hline & Experimento & Atividade & Mão na massa & Outras seções & \\
\hline Física & 42 & 9 & 4 & 7 & 62 \\
\hline Biologia & 19 & 26 & 8 & 10 & 63 \\
\hline Artes & 1 & 39 & 6 & 5 & 51 \\
\hline Química & 31 & 4 & 4 & 4 & 43 \\
\hline Matemática & ------------------ & 6 & 1 & 2 & 9 \\
\hline Astronomia & 2 & 1 & |-- & 1 & 4 \\
\hline Educação Física & 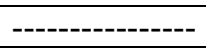 & 4 & 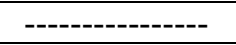 & |----------------- & 4 \\
\hline Português & 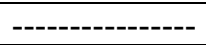 & 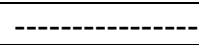 & 1 & 2 & 3 \\
\hline Geografia & |---------------- & 2 & |--------------" & |--------------- & 2 \\
\hline Total & 95 & 91 & 24 & 31 & 241 \\
\hline
\end{tabular}

Fonte: Dos autores, a partir de informações analisadas nas edições de 2009 a 2018 da CHC.

Algumas dessas atividades identificam a qual desses componentes curriculares (áreas) se referem (auto-intitulação). Os trechos a seguir da CHC mostram nossa interpretação dessa auto-intitulação. Algumas aparecem no título: "Travesseiro químico" (ed. 242, p. 19), outras nos textos das atividades: "Tantas informações sobre DNA inspiraram a equipe da CHC a fazer uma mistura de ciência e arte" (ed. 248, p. 20) e "Nada de truque, é pura física!" (ed. 233, p. 20).

Outras atividades, de acordo com a nossa interpretação, foram associadas às áreas a partir de termos específicos. Vale ressaltar que a separação não foi rígida e excludente, uma mesma atividade pode integrar assuntos de Física, Biologia e Química, outras, Física e Geografia, por exemplo. Identificamos como atividades de Biologia propostas que trazem conceitos relacionados à reciclagem e DNA. Na Química, conceitos de ácidos, bases e reações. Na área de Artes, consideramos propostas de pintura, dobraduras, recortes, modelagem de massinha. Em Matemática consideramos propostas que abordam formas geométricas. As atividades que tratam de Astronomia trazem conceitos relacionados aos astros e fenômenos celestes. As duas atividades de Geografia abordam a construção de mapas.

Identificamos, de acordo com a Tabela I, que a CHC propõe atividades experimentais para praticamente todas as Ciências, totalizando 184 atividades. Como a separação das atividades não foi excludente, uma mesma atividade pode estar em dois ou mais componentes, por abordar duas ou mais temáticas, isso explica o total geral contar 241 atividades.

Observamos também que algumas edições não apresentam propostas experimentais e outras trazem mais de uma. Das 241 atividades, a maioria aborda temas relacionados à 
Biologia com 63, seguida pela Física com 62 atividades. A Tabela I também mostra que a área com menor quantidade, apresentando 2 atividades experimentais, é a Geografia.

O Quadro II, a seguir, apresenta os resultados da primeira categorização: áreas tradicionais da Física. Esse Quadro mostra nas colunas os títulos das 63 atividades, as áreas da Física a que se referem e os conceitos ou expressões relacionadas à Física presentes nessas atividades experimentais na $\mathrm{CHC}$.

Quadro II - Atividades experimentais de Física nas edições de 2009 a 2018 da CHC.

\begin{tabular}{|c|c|c|c|c|}
\hline Ord. & Ed. & Título & Área & Conceito/expressão \\
\hline 1. & 198 & Deslizando pelo ar & Mecânica & $\begin{array}{l}\text { "Quanto mais rápido o seu movimento, maior a } \\
\text { resistência". }\end{array}$ \\
\hline 2. & 199 & O vampiro voador & Mecânica & $\begin{array}{l}\text { "Ligue o secador de cabelo e posicione o vampiro sobre } \\
\text { o fluxo de ar, de modo que ele fique flutuando". }\end{array}$ \\
\hline 3. & 200 & Copos musicais & Acústica & $\begin{array}{l}\text { "quanto mais rígido é o material, menos ele vibra, logo, } \\
\text { mais grave é o som". }\end{array}$ \\
\hline 4. & 201 & Pintura de cristal & Termologia & $\begin{array}{l}\text { "esses cristais se formam porque as moléculas de água } \\
\text { da tinta da sua pintura se juntam em um padrão regular } \\
\text { quando congelam". }\end{array}$ \\
\hline 5. & 205 & Pulgas de papel & Eletricidade & $\begin{array}{l}\text { "partículas elétricas" } \\
\text { "atraídos e repelidos" }\end{array}$ \\
\hline 6. & 206 & Avião magnético & Magnetismo & $\begin{array}{l}\text { "os ímãs produzem ao seu redor um campo magnético, } \\
\text { que atua como uma "força invisível"”. }\end{array}$ \\
\hline 7. & 210 & $\begin{array}{l}\text { Um presente } \\
\text { dobradinho }\end{array}$ & Mecânica & "fenômeno conhecido como capilaridade" \\
\hline 8. & 211 & $\begin{array}{l}\text { Viajando no } \\
\text { submarino de } \\
\text { plástico }\end{array}$ & Mecânica & "ficam mais leves do que a água e flutuam". \\
\hline 9. & 213 & Mágica no olhar & Óptica & $\begin{array}{l}\text { "o taumatrópio gira rapidamente, o desenho de um lado } \\
\text { surge antes do desenho do outro lado 'sumir' da } \\
\text { retina". }\end{array}$ \\
\hline 10. & 214 & Balão sem fogo & Termologia & "o ar quente é mais leve que o ar frio". \\
\hline 11. & 214 & $\begin{array}{l}\mathrm{O} \text { efeito estufa } \\
\text { diante de seus olhos }\end{array}$ & Termologia & $\begin{array}{l}\text { "o ar no interior da caixa foi aquecido pela luz que } \\
\text { passou pelo filme plástico". }\end{array}$ \\
\hline 12. & 214 & Experimente! & Termologia & $\begin{array}{l}\text { "com a boca quase fechada, o ar sai mais frio do que } \\
\text { com a boca aberta"7. }\end{array}$ \\
\hline 13. & 216 & $\begin{array}{l}\text { Sabão } \\
\text { superpoderoso }\end{array}$ & Mecânica & $\begin{array}{l}\text { "o sabão tem a capacidade de deixar a água, digamos, } \\
\text { mais penetrante". }\end{array}$ \\
\hline 14. & 223 & Elevador de passas & Mecânica & $\begin{array}{l}\text { "uva-passa afunda porque sua densidade é maior do } \\
\text { que a da água". }\end{array}$ \\
\hline 15. & 225 & $\begin{array}{l}\text { Experimentando } \\
\text { com a professora } \\
\text { Marie Curie }\end{array}$ & Mecânica & $\begin{array}{l}\text { "o ar é mais leve que a água". } \\
\text { "o ar existe e ocupa espaço". }\end{array}$ \\
\hline 16. & 226 & Som no copo! & Acústica & $\begin{array}{l}\text { "O ar dentro do copo passa a vibrar também, } \\
\text { aumentando, portanto, a intensidade do som". }\end{array}$ \\
\hline 17. & 228 & Feitiço para navegar & Mecânica & $\begin{array}{l}\text { "O detergente não é nenhuma poção mágica e, sim, } \\
\text { uma substância com poderes químicos para "quebrar" a } \\
\text { tensão superficial da água". }\end{array}$ \\
\hline 18. & 230 & Linhas Cruzadas & Acústica & $\begin{array}{l}\text { "A vibração se concentra em seu fundo e é transmitida } \\
\text { para o barbante". }\end{array}$ \\
\hline 19. & 232 & Vela que atrai água & Mecânica & "a pressão atmosférica do lado de fora é maior, ela \\
\hline
\end{tabular}

\footnotetext{
${ }^{7}$ Embora não seja objetivo desse trabalho, identificamos erro conceitual na explicação dessa atividade.
} 


\begin{tabular}{|c|c|c|c|c|}
\hline & & & & empurra a água do prato para dentro". \\
\hline 20. & 233 & $\begin{array}{l}\text { Bexiga a prova de } \\
\text { fogo }\end{array}$ & Termologia & $\begin{array}{l}\text { "Cheia de água, o calor do fogo recebido pela borracha } \\
\text { é rapidamente transferido ao líquido". }\end{array}$ \\
\hline 21. & 234 & $\begin{array}{l}\text { Arco-íris dentro de } \\
\text { casa! }\end{array}$ & Óptica & $\begin{array}{l}\text { "Cada uma dessas cores sofre um desvio diferente e o } \\
\text { resultado é a separação da luz branca". }\end{array}$ \\
\hline 22. & 235 & Sal congelante & Termologia & "temperatura de fusão" \\
\hline 23. & 236 & $\begin{array}{l}\text { "Força" para atrair } \\
\text { bolhas }\end{array}$ & Eletricidade & $\begin{array}{l}\text { "Os prótons são partículas de carga positiva e os } \\
\text { elétrons, de carga negativa". }\end{array}$ \\
\hline 24. & 240 & Física para regar & Mecânica & "dar um banho de física!" \\
\hline 25. & 241 & $\begin{array}{l}\text { Derretimento } \\
\text { colorido }\end{array}$ & Termologia & "mudança de estado da água de sólido para líquido" \\
\hline 26. & 243 & Bolinha flutuante & Eletricidade & $\begin{array}{l}\text { "as bolinhas de isopor sofrem atrito com a parede do } \\
\text { recipiente". }\end{array}$ \\
\hline 27. & 244 & $\begin{array}{l}\text { Pipoca para todo } \\
\text { mundo }\end{array}$ & Termologia & $\begin{array}{l}\text { "o vapor d'água superaquecido fica sob pressão no } \\
\text { interior do grão de milho". }\end{array}$ \\
\hline 28. & 244 & O ovo mágico & Mecânica & $\begin{array}{l}\text { "[ovo] é menos denso do que a água misturada com } \\
\text { sal". }\end{array}$ \\
\hline 29. & 246 & Minissubimarino & Mecânica & "submarino mais denso do que o líquido" \\
\hline 30. & 250 & O quique mais alto & Mecânica & "energia da bola"; "energia cinética" \\
\hline 31. & 251 & Teste do Talco & Mecânica & "rompendo a tal tensão superficial" \\
\hline 32. & 253 & $\begin{array}{l}\text { Termômetro de } \\
\text { água }\end{array}$ & Termologia & "Objetivo: construir um termômetro" \\
\hline 33. & 253 & Gira gira das cores & Óptica & "ilusão de ótica" \\
\hline 34. & 254 & Chuva particular & Termologia & "a água quente se condensa". \\
\hline 35. & 255 & Águas separadas & Mecânica & "água salgada mais densa..." \\
\hline 36. & 257 & Pintor de flores & Mecânica & "O nome desse fenômeno é capilaridade". \\
\hline 37. & 258 & $\begin{array}{l}\text { Fórmula da } \\
\text { Invisibilidade }\end{array}$ & Óptica & "a glicerina reflete a luz". \\
\hline 38. & 260 & Desvio da luz & Óptica & "capacidade de desviar a luz" \\
\hline 39. & 262 & $\begin{array}{l}\text { Água quente, água } \\
\text { fria }\end{array}$ & Mecânica & "a água fria é mais densa do que a água quente". \\
\hline 40. & 263 & Plástico voador & Eletricidade & "elétrons em excesso"; "eles se repelem". \\
\hline 41. & 263 & Mapa de papel & Mecânica & "pontos de referência (praças, pontes..." \\
\hline 42. & 267 & $\begin{array}{l}\text { O truque da vela de } \\
\text { laranja }\end{array}$ & Mecânica & $\begin{array}{l}\text { "O segredo aqui é um fenômeno chamado } \\
\text { capilaridade". }\end{array}$ \\
\hline 43. & 270 & $\begin{array}{l}\text { Aqui tá quente! Ali } \\
\text { tá frio! }\end{array}$ & Termologia & $\begin{array}{l}\text { "a água (e as ligações entre suas moléculas) tem } \\
\text { propriedades especiais capazes de manter sua } \\
\text { temperatura por mais tempo". }\end{array}$ \\
\hline 44. & 270 & Berimbalina & Acústica & "pegue os palitos e tire um som das cordas". \\
\hline 45. & 271 & Sombra com cores? & Óptica & $\begin{array}{l}\text { "O anteparo é algo que impede a passagem de luz } \\
\text { formando uma sombra". }\end{array}$ \\
\hline 46. & 271 & $\begin{array}{l}\text { Onde a luz faz a } \\
\text { curva }\end{array}$ & Óptica & $\begin{array}{l}\text { "Isso é o resultado de um fenômeno chamado } \\
\text { refração". }\end{array}$ \\
\hline 47. & 271 & $\begin{array}{l}\text { Desenhista de } \\
\text { silhuetas }\end{array}$ & Óptica & $\begin{array}{l}\text { "Seu modelo deve ficar de lado em relação à luz para } \\
\text { que sua sombra seja projetada no papel". }\end{array}$ \\
\hline 48. & 271 & Mágica das cores & Óptica & $\begin{array}{l}\text { "se você coloca o papel colorido cobrindo a luz da } \\
\text { lanterna e ilumina os objetos, de quais cores eles se } \\
\text { tornam?" }\end{array}$ \\
\hline 49. & 271 & Teatro de sombras & Óptica & $\begin{array}{l}\text { "Acenda o abajur, deite na cama e comece a projetar a } \\
\text { sombra das suas mãos na parede". }\end{array}$ \\
\hline 50. & 272 & Gelo acelerado & Termologia & "super-resfriamento ou sobrefusão" \\
\hline 51. & 273 & $\begin{array}{l}\text { Porque as coisas } \\
\text { caem? }\end{array}$ & $\begin{array}{l}\text { Física } \\
\text { Moderna }\end{array}$ & $\begin{array}{l}\text { "mostrou que os corpos caem porque eles escorregam } \\
\text { no espaço que esta deformado por um corpo mais } \\
\text { pesado". }\end{array}$ \\
\hline 52. & 274 & Balão anjo & Eletricidade & $\begin{array}{l}\text { "Como cargas iguais se repelem, o balão e o anel de } \\
\text { plástico acabam se afastando". }\end{array}$ \\
\hline 53. & 275 & Pão pula-pula & Mecânica & "o pão fica mais leve e sobe para a superfície da água". \\
\hline
\end{tabular}




\begin{tabular}{|c|c|c|c|c|}
\hline 54. & 276 & $\begin{array}{l}\text { Açúcar ou } \\
\text { adoçante? }\end{array}$ & Mecânica & "a densidade da bebida com açúcar é maior”. \\
\hline 55. & 278 & Quente ou frio? & Termologia & $\begin{array}{l}\text { "sensações de quente ou frio podem variar de acordo } \\
\text { com a temperatura do nosso corpo?" }\end{array}$ \\
\hline 56. & 283 & Lava engasgada & Mecânica & $\begin{array}{l}\text { "ao adicionarmos o comprimido efervescente a água } \\
\text { com corante parece ficar menos densa". }\end{array}$ \\
\hline 57. & 284 & $\begin{array}{l}\text { Três mascotes e um } \\
\text { jardim no potinho }\end{array}$ & Termologia & "A água usada para regar as sementes evaporou-se". \\
\hline 58. & 288 & Física para regar & Mecânica & $\begin{array}{l}\text { "você vai construir um regador diferente }[\ldots] \text { e, de } \\
\text { quebra, dar um banho de física!" }\end{array}$ \\
\hline 59. & 291 & As cores da luz & Óptica & "O resultado foi a decomposição da luz em cores". \\
\hline 60. & 297 & Flor de arco-íris & Mecânica & $\begin{array}{l}\text { "processo, chamado capilaridade, permite que a água } \\
\text { absorvida pelas raízes seja distribuída por todo o corpo } \\
\text { da planta". }\end{array}$ \\
\hline 61. & 302 & Cadê a sombra? & Óptica & $\begin{array}{l}\text { "porque um objeto só projeta sombra se a luz não } \\
\text { passar através dele". }\end{array}$ \\
\hline 62. & 306 & Para lá ou para cá? & Óptica & $\begin{array}{l}\text { "A seta mudou de sentido! Isso aconteceu porque a luz } \\
\text { que passa pela garrafa é desviada". }\end{array}$ \\
\hline
\end{tabular}

Fonte: Dos autores, a partir de informações analisadas nas edições de 2009 a 2018 da CHC.

O Quadro II mostra que das 109 edições analisadas encontramos atividades experimentais que tratam de temas da Física em 52, totalizando 62 atividades. Algumas edições trazem mais de uma proposta. A edição 271, comemorativa de 2015 - Ano Internacional da Luz, apresentou 5 atividades de Física ${ }^{8}$. Como era de se esperar são propostas de óptica.

As propostas tratam de várias áreas da Física, sendo a mais abordada a mecânica (24), seguida da termologia (14) e da óptica (13). As áreas menos abordadas são a eletricidade (5), a acústica (4), o magnetismo (1) e a física moderna (1).

Dentre as atividades de mecânica o conteúdo que mais aparece está relacionado à densidade (construção de submarinos, mistura de substâncias de densidades diferentes, comportamento de objetos mergulhados em água com sal ou contendo comprimidos efervescentes). $\mathrm{Na}$ termologia prevalecem as atividades que tratam da mudança de fase da água (congelando, condensado ou solidificando), em óptica o fenômeno da refração (produção de arco-íris, observação de imagens através de lâminas de água) e em acústica a construção de instrumentos musicais (utilizando colunas de líquidos e cordas). Todas as propostas que abordam eletricidade propõem atividades com os processos de eletrização (utilizando pedacinhos de papel ou balões). A atividade de magnetismo propõe a construção de um avião que fica suspenso a partir da atração de clipes fixados em suas asas e um ímã que está nas mãos de quem realiza a atividade.

\footnotetext{
${ }^{8}$ A revista já fez edições comemorativas do Ano Internacional da Astronomia, da Química, da Biodiversidade, da Cooperação pela Água, entre outras.
} 
A proposta de física moderna aborda a gravitação a partir da teoria da relatividade geral. Usando um lençol e bolas de massas diferentes (gude e de bilhar) procura mostrar a deformação do espaço causada pelo movimento dessas bolas (Fig. 2).

A maioria das atividades é simples de ser realizada, nenhuma delas envolve equações ou tratamento numérico. Os materiais utilizados são de fácil aquisição e não apresentam riscos (algumas delas recomendam que se recorra a um adulto), para a faixa etária a que se propõe a revista, 7 a 14 anos.

\section{Atividades experimentais de Física da CHC}

$\mathrm{Na}$ segunda categoria de análise apresentamos a forma de encaminhamento das atividades experimentais, a qual apresenta relação com a concepção de Natureza da Ciência, procurando compreender o caráter investigativo das atividades. Para tanto analisamos a estrutura das propostas.

Em todas as revistas analisadas as seções que propõem experimentos são organizadas em quatro etapas que identificamos como: 1) imagem e contextualização, 2) materiais, 3) procedimentos e 4) resultados.

1) Imagem e contextualização - a CHC inicia as atividades com uma imagem e um texto envolvendo uma situação do dia-a-dia relacionada ao assunto tratado. Esse texto apresenta também algumas perguntas. As imagens nas Fig. 1 e 2 a seguir são exemplos dessa etapa.

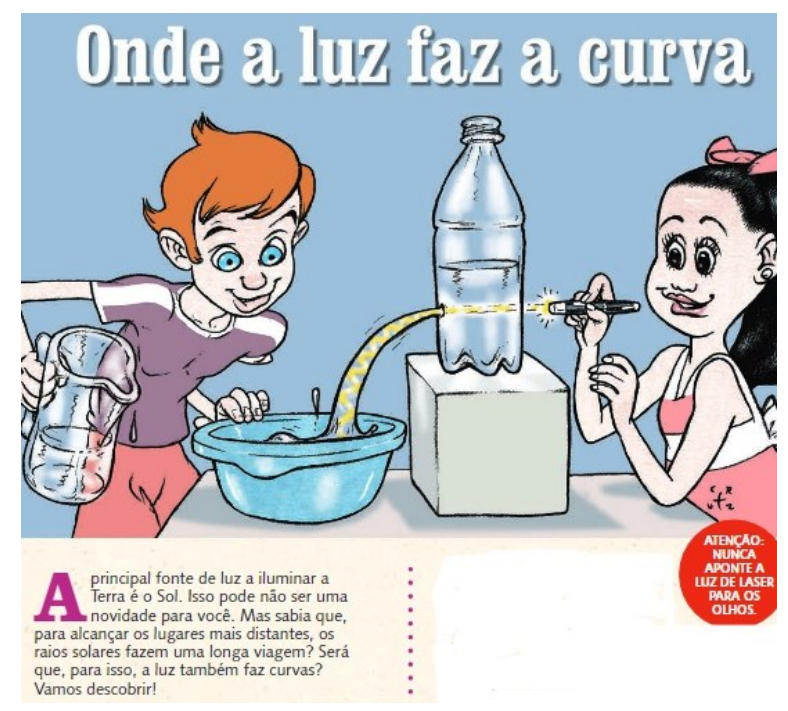

Fig. 1 - Imagem e contextualização das atividades experimentais (CHC, 2015, ed. 271, p. 17). 


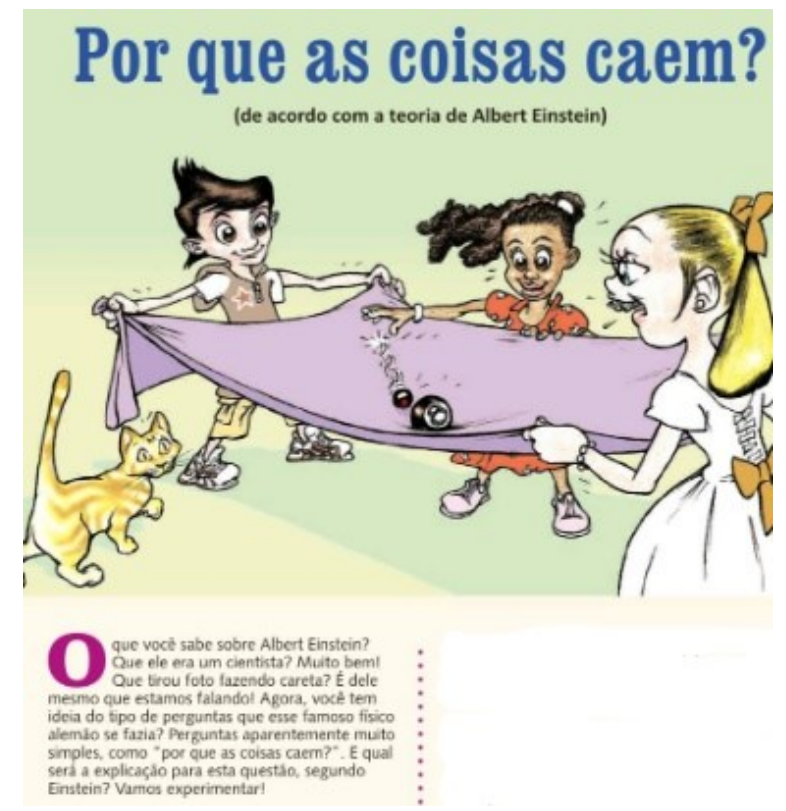

Fig. 2 - Imagem e contextualização das atividades experimentais (CHC, 2015, ed. $273, p .16)$.

2) Materiais - os materiais necessários para a realização das atividades experimentais são descritos nos tópicos chamados de: "Você vai precisar de" e "Material necessário". As Fig. 3 e 4 a seguir mostram exemplos dessa etapa.

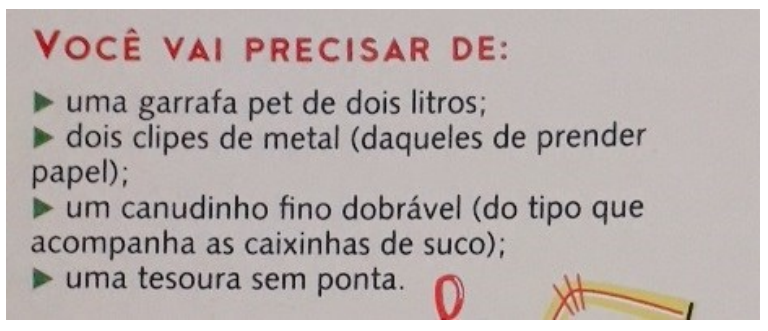

Fig. 3 - Apresentação dos materiais (CHC, 2013, ed. 246, p. 18).

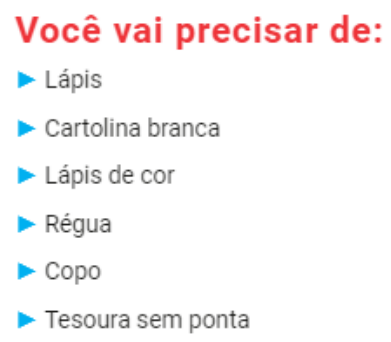

Fig. 4 - Apresentação dos materiais (CHC, 2018, ed. 2919).

\footnotetext{
${ }^{9}$ Houve mudanças no sítio da CHC: a partir da edição 288 de abril de 2017 não é possível baixar a edição inteira paginada, somente as matérias.
} 
3) Procedimentos - as orientações para a realização das atividades experimentais são apresentadas como "Mãos à obra", "Como fazer" e "Passo a passo", conforme exemplos mostrados nas Fig. 5 e 6.

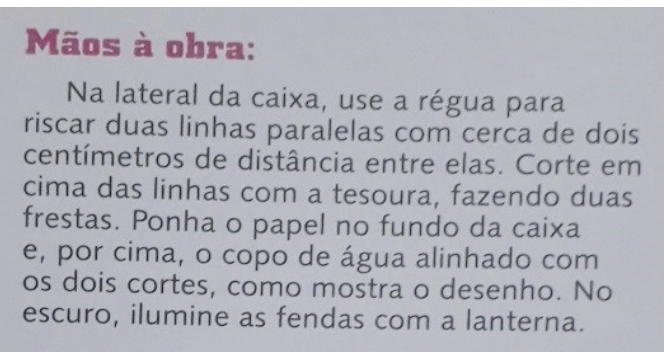

Fig. 5 - Procedimentos de realização das atividades (CHC, 2014, ed. 260, p. 18).

\section{Modo de fazer:}

Encha um pouco mais da metade do copo com a água com gás. Depois, coloque um pedaço de pão e observe... Pulou? Não? Então, tente com um pedacinho menor... E agora? Se nâo pulou, tente com um menor ainda... Agora vai!

Veja que o pão fica subindo e descendo, saltitando dentro do copo!

Fig. 6 - Procedimentos de realização das atividades (CHC, 2016, ed. 275, p. 18).

4) Resultados - na última etapa das atividades são descritos os resultados esperados e as explicações dos fenômenos físicos abordados. Essa etapa é chamada de "O que aconteceu?" ou “O que acontece?", como exemplificado nas Fig. 7 e 8.

Para entender a lógica dos copos musicais, precisamos

saber primeiro que: quanto mais rígido é o material,

menos ele vibra, logo, mais grave é o som. Assim, quanto

maior a quantidade de água no copo, menor é a

frequência, e, portanto, mais grave é o som. Por isso, é

que a arrumação dos copos musicais deve se dar da

esquerda para a direita, do mais cheio ao mais vazio - ou

do mais grave ao mais agudo -, permitindo que 0

instrumento improvisado seja tocado como um piano.

Fig. 7 -Resultados das atividades experimentais (CHC, 2009, ed. 200, p. 20). 


\section{0 que aconteceu?}

A seta mudou de sentido! Isso aconteceu porque a luz que passa pela garrafa é desviada. Assim,

a ponta da direita aparece no lado esquerdo e o finalzinho da seta aparece do outro lado.

Fig. 8 - Resultados das atividades experimentais (CHC, 2018, ed. 306 ${ }^{10}$ ).

A Fig. 9 a seguir mostra uma proposta completa da CHC. Nela podemos observar todas as etapas mencionadas anteriormente.

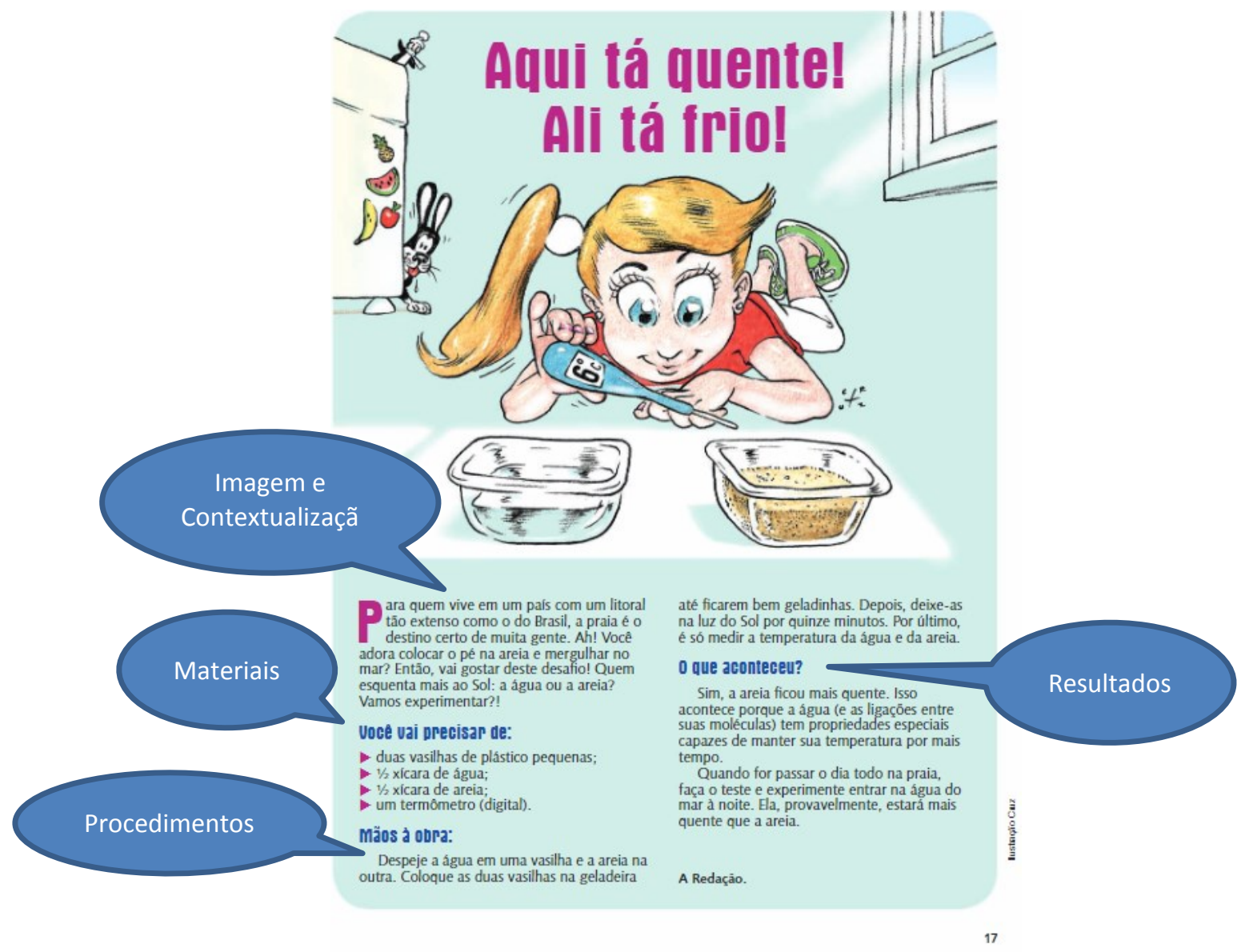

Fig. 9 - Atividades experimental (CHC, 2015, ed. 270, p. 17).

A primeira etapa das atividades, ao contextualizar o tema, traz o problema a ser respondido, às vezes na forma de uma pergunta: Quem esquenta mais ao Sol: a água ou a areia? (Fig. 9). Além disso, aparecem outras questões que podem ajudar a identificar conhecimentos prévios e despertar a curiosidade dos estudantes: $\mathrm{O}$ que você sabe sobre Albert Einstein? (Fig. 2). As duas etapas seguintes apresentam uma sequência rígida e fechada ao descrever os materiais e os procedimentos.

\footnotetext{
${ }^{10}$ Houve mudanças no sítio da CHC, a partir da edição 288 de abril de 2017 não é possível baixar a edição inteira paginada, somente as matérias.
} 
Os procedimentos apresentam-se em forma de um roteiro, apontando cada ação para realização das atividades. Essa etapa chega a se auto intitular de "Passo a passo". Essa perspectiva retrata atividades centradas em uma percepção inadequada do método científico, apresentando uma sequência mecânica de procedimentos a serem seguidos, não deixa espaço para dúvidas, tentativas e erros, não reflete as características reais do trabalho científico, onde a criatividade e a intuição são fundamentais.

A última etapa caracteriza mais fortemente aspectos da visão empírico-indutivista. Com o caráter rígido e exato, as propostas determinam um único caminho a ser seguido e uma resposta correta. Das 63 atividades experimentais de Física analisadas todas apresentam os procedimentos a serem seguidos e somente 5 não apresentam respostas com a interpretação dos resultados. Nesse sentido, mais de 90\% das propostas de Física, possuem grau de liberdade zero. Apresentam os resultados, as etapas do desenvolvimento da experimentação são predeterminadas e o estudante tem o papel de executor passivo. Os verbos no imperativo afirmativo, que podem ser observados nas figuras anteriores, têm presença marcante em todas as propostas na etapa dos procedimentos como, por exemplo: "use", “corte", "ponha", "ilumine", "coloque".

A revista utiliza metáforas e analogias para facilitar a compreensão de conceitos científicos. Inadequadamente aparecem analogias entre os conceitos de densidade e peso, associando o mais denso ao pesado e o menos denso ao leve, "o ar é mais leve que a água", “o pão fica mais leve e sobe", "o ar quente é mais leve que o ar frio". No Quadro II, podemos observar essas analogias nas linhas 8, 10, 15 e 54 .

Metáforas, imagens e analogias podem contribuir para no ensino de Ciências, porém, o uso inadequado desses elementos afeta a abstração dos problemas quando se autoexplicam deixando para o leitor a função de estabelecer as correspondências entre a analogia e o conhecimento/conceito estudado. Um exemplo dessa autoexplicação está na linha 43 do Quadro II, quando a atividade afirma que "a água tem propriedades especiais". A CHC utiliza-se da expressão especial para se referir a uma propriedade física da água e não discute o fenômeno.

O uso desses elementos pode impedir a reflexão crítica e a abstração, e consequentemente, a evolução dos conhecimentos dos estudantes. Reforça explicações equivocadas para o conceito ao permanecer na concepção realista ingênuo e/ou empirista da Ciência.

Vale ressaltar que a inadequação no uso das analogias não aparece em todas as atividades, os textos da $\mathrm{CHC}$ têm autorias diversas. Algumas têm a autoria nominalmente explicitada (pesquisador/instituição) outras são assinadas pela redação da revista (Fig. 9). Acreditamos que devido a essa diversidade de autores as atividades abordam de formas diferentes um mesmo conceito. Nas linhas 28, 29, 35 e 39 não encontramos analogia inadequada entre densidade e peso. 
Considerando os problemas identificados nas atividades experimentais da $\mathrm{CHC}$ (propostas fechadas afastadas de uma abordagem investigativa) e o grande número de escolas públicas do Brasil que recebem a revista, acreditamos que o professor pode modificar as propostas, caso queira utilizá-las em suas aulas.

Todas as atividades experimentais de Física da CHC apresentam uma sequência de etapas, neste trabalho identificamos como: 1) imagem e contextualização, 2) materiais, 3) procedimentos e 4) resultados. Essas etapas não precisam ser seguidas rigidamente, e nem mesmo devem ser apresentadas aos estudantes, como recomenda Laburú (2003, p. 241), "não vemos importância didática na explicitação ou no ensinamento das mesmas [etapas], de modo a requerer dos alunos que sigam ou se enquadrem numa sequência rígida e fixa de passos ou a uma lista de processos, mas que poderão surgir naturalmente ou por necessidade da própria provocação discursiva".

Na primeira etapa (imagem e contextualização) a CHC apresenta o fenômeno e a questão a ser respondida, que podemos chamar de problema. Problema para Borges (2002, p. 303) é como um desafio proposto para os estudantes responderem, "uma situação para a qual não há uma solução imediata obtida pela aplicação de uma fórmula ou algoritmo".

Pesquisadores indicam que o professor, com domínio teórico do conteúdo abordado, pode (re)formular o problema, elaborando outras questões relacionadas ao fenômeno e a partir delas convidar os estudantes a levantar hipóteses, oportunizando diálogos para identificar conhecimentos prévios (BORGES, 2002; GOMES; BORGES; JUSTI, 2008). As duas próximas etapas (escolha dos materiais e procedimentos) podem ser discutidas e organizadas com base nas discussões sobre o problema a ser respondido. Pode-se evitar uma lista de materiais e de procedimentos e privilegiar a participação dos estudantes: que materiais serão necessários? Quais estratégias poderemos organizar para realizar a atividade?

Identificamos na $\mathrm{CHC}$ atividades experimentais poucos problemas mais complexos para a faixa etária a que se destina (exemplo: Figura 2). Caso o professor queira propor essas atividades poderá trabalhar com um grau de liberdade menor, recomendando os materiais e orientando os procedimentos durante a realização da atividade.

Julgamos importante, porém, que os resultados não sejam apresentados aos estudantes durante o desenvolvimento de nenhuma das propostas, sejam elas simples ou mais complexas. Quando a importância da atividade tem o foco nos resultados, perde-se a riqueza da aprendizagem durante o processo. Borges (2002, p. 300) escreve sobre a insegurança dos estudantes na sua relação com o erro. Quando não atinge o resultado esperado, o estudante

fica desconcertado com seu erro, mas, se percebe que o 'erro' pode afetar suas notas, ele intencionalmente 'corrige' suas observações e dados para obter a 'resposta correta', e as atividades experimentais passam a ter o caráter de um jogo viciado. Infelizmente este é daquele tipo de jogo que se aprende a jogar muito rapidamente. Muitas vezes, os próprios professores são vítimas desse raciocinio, $e$ sentem-se inseguros quando as atividades que propõem não funcionam como esperavam, passando a evitá-las no futuro porque 'não dão certo'. As causas do 
erro não são investigadas e uma situação potencialmente valiosa de aprendizagem se perde, muitas vezes, por falta de tempo. Nesse sentido, o que se consegue no laboratório é similar ao que se aprende na sala de aula, onde o resultado se torna mais importante que o processo, em detrimento da aprendizagem.

Raicik; Peduzzi e Angotti (2018, p. 124-125), procurando mostrar uma nova imagem da filosofia de Francis Bacon, citam que no ensino, o questionamento, a reflexão na pesquisa e a existência dos erros "podem ser instigados pelo professor, a fim de se gerar discussões sobre o contexto de desenvolvimento da ciência em sala de aula e, consequentemente, analisar a relevância e o papel da experimentação em uma dimensão mais favorável e não restringida".

A CHC não explicita encaminhamentos para realização das atividades experimentais em grupo. Os verbos de ordem, no imperativo, aparecem nos procedimentos no singular: corte, despeje, encha. Em algumas imagens aparecem mais de uma criança envolvida na atividade (Fig. 1 e 2), em outras, apenas uma criança manipula os materiais (Fig. 9).

Acreditando nos pressupostos de um ensino com base na alfabetização científica e em visões mais adequadas do fazer científico, o professor poderia privilegiar a realização das atividades experimentais da $\mathrm{CHC}$ em grupo. Atividades experimentais realizadas de forma coletiva podem proporcionar a abordagem de fatores éticos como, a solidariedade, a empatia e respeito às opiniões dos integrantes do grupo. Incentivar o trabalho em grupo pode contribuir para refletir criticamente sobre concepções de que o trabalho científico não é uma atividade de 'gênios solitários'e ajuda a superar as visões elitistas e individualistas da Ciência (GILPEREZ et al., 2001).

Criar espaço para apresentar hipóteses e estratégias para realização das atividades, além de deixar os estudantes mais à vontade para encontrar resultados inesperados, evidenciará a importância da criatividade no processo de construção do conhecimento científico. Dessa forma, modificando o formato rígido e fechado das atividades experimentais da revista $\mathrm{CHC}$, o professor poderá minimizar seus aspectos empírico-indutivista.

\section{Considerações}

A CHC é um periódico de abrangência nacional. Em 1991, passa a ser distribuída pelo MEC às escolas públicas dos anos iniciais do ensino fundamental no Brasil para compor $\mathrm{o}$ acervo de suas bibliotecas. As atividades experimentais da $\mathrm{CHC}$ abordam diversos componentes curriculares, sendo a Física um dos mais presentes.

A revista trata de várias áreas da Física, sendo a maior parte das atividades da área de mecânica. Em magnetismo e física moderna encontramos somente uma atividade. Essa pesquisa analisou 109 revistas, dessas, 52 trazem atividades experimentais de Física, totalizando 62 atividades, algumas revistas trazem duas ou mais atividades.

As seções que propõem experimentos estão organizadas em quatro etapas. Somente a primeira oportuniza, algumas vezes, o diálogo com os estudantes, podendo identificar 
conhecimentos prévios. Duas outras etapas apresentam uma sequência rígida e fechada ao determinar os materiais e procedimentos em forma de um roteiro do passo a passo da realização das atividades. A maior parte das atividades de Física (58) possui grau de liberdade zero, uma vez que a última etapa traz os resultados das atividades, característica marcante da visão empírico-indutivista.

A CHC é reconhecida e acreditamos que, além de pareceristas dessa revista, ela passe por avaliações periódicas durante o processo de seleção de obras no PNLD, programa que conta com investimento de milhões de reais do Ministério da Educação.

A revista não é material didático e não explicita entre seus objetivos a alfabetização científica. Porém, considerando as pesquisas em ensino de Ciências das últimas décadas, acreditamos que um material que pode compor as bibliotecas de mais de 60 mil escolas públicas brasileiras não deveria encaminhar concepções estereotipadas da Ciência como, por exemplo, a visão empírico-indutivista. Pelas dimensões do PNLD e sua política de avaliação dos materiais distribuídos, a $\mathrm{CHC}$ deveria se destacar como mediadora entre as pesquisas e o ensino nas escolas. Essas pesquisas afirmam que os estudantes desde os anos iniciais do ensino fundamental devem realizar atividades que demandem reflexão, discussões, explicações e organização de relatos. Esses estudantes não devem atuar apenas de forma contemplativa.

A visão empírico-indutivista é uma das mais criticadas nas pesquisas em ensino de Ciências. Porém, a análise mostrou características dessa concepção inadequada da Ciência, marcada por uma visão rígida, com pouca ou nenhuma liberdade intelectual para atuação dos estudantes nas atividades experimentais propostas pela CHC. Acreditamos que iniciar o ensino de Ciências a partir de atividades com esse encaminhamento é um desestímulo ao público-alvo da revista naturalmente inquieto, criativo e curioso. As atividades experimentais propostas dessa forma contrariam concepções de um ensino que promova a alfabetização científica.

A CHC é distribuída pelo PNLD, mas diferente do livro adotado, não constitui a base didática para o trabalho do professor. Porém a presença da revista na escola, mesmo que de forma complementar não pode ser negligenciada. Conforme já citamos, o professor, a partir de um bom domínio teórico das temáticas abordadas, pode modificar a estrutura das atividades, dessa forma, poderia minimizar seus aspectos empírico-indutivistas.

Acreditamos que essa pesquisa possa contribuir na compreensão da natureza das atividades experimentais da revista e colaborar para que professores compreendam limites e potencialidades da $\mathrm{CHC}$ no processo de ensino-aprendizagem.

\section{Referências}

ALMEIDA, S. A. de Interações e práticas de letramento mediadas pelo uso da revista Ciência Hoje das Crianças (CHC) em sala de aula. 2011. 270p. Tese (Doutorado) Faculdade de Educação, Universidade de São Paulo, São Paulo. 
ALMEIDA, S. A. de Cenas de leitura da Ciência Hoje das Crianças: modos de uso e apropriação da revista em sala de aula. Educação em Revista, Belo Horizonte, n. 34, e 173829, p. 1-28, 2018.

ALMEIDA, S. A. de; GIORDAN, M. A revista Ciência Hoje das Crianças no letramento escolar: a retextualização de artigos de divulgação científica. Educação e Pesquisa, São Paulo, v. 40, n. 4, p. 999-1014, 2014.

ALMEIDA, S. A. de; LIMA, M. E. C. Cientistas em revista: Einstein, Darwin e Marie Curie na Ciência Hoje das Crianças. Ensaio Pesquisa em Educação em Ciências, Belo Horizonte, v. 18, n. 2, p. 29-47, 2016.

ARAÚJO, M. S.T. de; ABIB, M. L. V. dos S. Atividades experimentais no ensino de física: diferentes enfoques, diferentes finalidades. Revista Brasileira de Ensino de Física, Florianópolis, v. 25, n. 2, p. 176-194, 2003.

AZEVEDO, M. C. P. S. Ensino por investigação: problematizando as atividades em sala de aula. In: CARVALHO, A. M. P. de. (org) Ensino de Ciências: Unindo a pesquisa e a prática. São Paulo: Pioneira Thomson Learning, 2004. cap. 2. p. 19-33.

BACHELARD, G. A formação do espírito científico: contribuição para uma psicanálise do conhecimento. Tradução: Esteia dos Santos Abreu. Rio de Janeiro: Contraponto, 1996. 316 p.

BORGES, A. T. Novos rumos para o laboratório escolar de ciências. Caderno Brasileiro de Ensino de Física, Florianópolis, v. 19, n. 3, p. 291-313, 2002.

CACHAPUZ, A.; GIL-PEREZ, D.; CARVAlHO, A. M. P. de; PRAIA, J.; VILCHES, A. A necessária renovação do ensino das ciências. São Paulo: Cortez, 2005. 264 p.

CARVAlHO, A. M. P. de. As práticas experimentais no ensino de física. In: CARVALHO, A. M. P. de. (org) Ensino de Física. São Paulo: Cengage Learning, 2010. 158 p.

CARVAlHO, A. M. P. de; VANNUCHI, A. I.; BARROS, M. A.; GONÇALVES, M. E. R.; REY, R. C. de. Ciências no Ensino Fundamental: o conhecimento físico. São Paulo: Scipioni, 2010. 188 p.

CHALMERS, A. F. O que é ciência afinal? Tradução: Raul Filker. Editora Brasiliense. 1993. $225 \mathrm{p}$. 
GALIETA, T. Possibilidades de inserção de textos da revista Ciência Hoje das Crianças nas séries iniciais: explorando concepções de leitura de futuros professores. Ensino de Ciências e Tecnologia em Revista, v. 3, n. 2, p. 01-24, 2013.

GIL-PEREZ, D.; MONTORO, I. F.; ALÍS, J. C.; CACHAPUZ, A.; PRAIA, J. Para uma imagem não deformada do trabalho científico. Ciência \& Educação, Bauru, v. 7, n. 2, p. 125 $153,2001$.

GODOY. A. S. Pesquisa qualitativa tipos fundamentais. Revista de Administração de Empresas, São Paulo, v. 35, n. 3, p. 20-29,1995.

GOMES, A. D. T.; BORGES, A. T.; JUSTI, R. Processos e conhecimentos envolvidos na realização de atividades práticas: revisão da literatura e implicações para a pesquisa. Investigações em Ensino de Ciências, Porto Alegre, v. 13, n. 2, p. 187-207, 2008.

LABURÚ, C. E. Problemas abertos e seus problemas no laboratório de física: uma alternativa dialética que passa pelo discursivo multivocal e univocal. Investigações em Ensino de Ciências, v. 8, n. 3, p. 231-256, 2003.

LABURÚ, C. E. Seleção de experimentos de física no ensino médio: uma investigação a partir da fala dos professores. Investigação em Ensino de Ciências, Porto Alegre, v. 10, n. 2, p. 161-178, 2005.

LOPES, A. R. C. Bachelard: o filósofo da desilusão. Caderno Catarinense de Ensino de Física, v. 13, n. 3, p. 248-273, 1996.

MORAES, R. Análise de conteúdo. Revista Educação, Porto Alegre, v. 22, n. 37, p. 7-32, 1999.

MOREIRA, M. A.; MASSONI, N. T.; OSTERMANN, F. "História e epistemologia da física" na licenciatura em física: uma disciplina que busca mudar concepções dos alunos sobre a natureza da ciência. Revista Brasileira de Ensino de Física, Florianópolis, v. 29, n. 1, p. 127-134, 2007.

RAICIK, A. C.; PEDUZZI, L. O. Q.; ANGOTTI, J. A. P. Experimentos exploratórios e experientia literata: (re) pensando a experimentação. Investigações em Ensino de Ciências, v. 23, n. 1, p. 111-129, 2018. 
PEREIRA, M. V.; MOREIRA, M. C. do A. Atividades prático-experimentais no ensino de física. Programa de Pós-graduação em Ensino de Ciências, Instituto Federal do Rio de Janeiro. Caderno Brasileiro de Ensino de Física, Florianópolis, v. 34, n. 1, p. 265-277, 2017.

RIBEIRO, R. A.; KAWAMURA, M. R. D. Divulgação científica para o público infantil: potencialidades da revista Ciência Hoje das Crianças. In: SIMPÓSIO NACIONAL DE ENSINO DE FÍSICA, XIX, 2011, Manaus, AM. Atas...

SASSERON, L. H.; MACHADO, V. F. Alfabetização Científica na prática: Inovando a forma de Ensinar Física. 1. ed. São Paulo: Editora Livraria da Física. 2017. 112 p.

SILVA, L. L. da; PIMENTEL, N. L.; TERRAZZAN, E. As analogias na revista de divulgação científica Ciência hoje das crianças. Ciência \& Educação, Bauru, v. 17, n. 1, p. 163-181, 2011.

ZÔMPERO, A. F.; LABURÚ, C. E. Atividades investigativas no ensino de ciências: aspectos históricos e diferentes abordagens. Ensaio Pesquisa em Educação em Ciências, v. 13, n. 3, p. 67-80, 2011.

\section{Referências dos textos analisados}

INSTITUTO CIÊNCIA HOJE. Revista Ciência Hoje das Crianças. SBPC, São Paulo, edições: janeiro de 2009 a dezembro de 2018. 